\title{
Trends in the Binding of Cell Penetrating Peptides to siRNA: A Molecular Docking Study
}

\author{
P. V. G. M. Rathnayake, ${ }^{1}$ B. G. C. M. Gunathunge, ${ }^{2}$ P. N. Wimalasiri, ${ }^{2}$ \\ D. N. Karunaratne, ${ }^{1,2}$ and R. J. K. U. Ranatunga ${ }^{1,2}$ \\ ${ }^{1}$ Postgraduate Institute of Science, University of Peradeniya, 20400 Peradeniya, Sri Lanka \\ ${ }^{2}$ Department of Chemistry, University of Peradeniya, 20400 Peradeniya, Sri Lanka
}

Correspondence should be addressed to R. J. K. U. Ranatunga; udyranatunga@pdn.ac.lk

Received 28 October 2016; Accepted 15 January 2017; Published 21 February 2017

Academic Editor: Jianwei Shuai

Copyright (C) 2017 P. V. G. M. Rathnayake et al. This is an open access article distributed under the Creative Commons Attribution License, which permits unrestricted use, distribution, and reproduction in any medium, provided the original work is properly cited.

\begin{abstract}
The use of gene therapeutics, including short interfering RNA (siRNA), is limited by the lack of efficient delivery systems. An appealing approach to deliver gene therapeutics involves noncovalent complexation with cell penetrating peptides (CPPs) which are able to penetrate the cell membranes of mammals. Although a number of CPPs have been discovered, our understanding of their complexation and translocation of siRNA is as yet insufficient. Here, we report on computational studies comparing the binding affinities of CPPs with siRNA, considering a variety of CPPs. Specifically, seventeen CPPs from three different categories, cationic, amphipathic, and hydrophobic CPPs, were studied. Molecular mechanics were used to minimize structures, while molecular docking calculations were used to predict the orientation and favorability of sequentially binding multiple peptides to siRNA. Binding scores from docking calculations were highest for amphipathic peptides over cationic and hydrophobic peptides. Results indicate that initial complexation of peptides will likely occur along the major groove of the siRNA, driven by electrostatic interactions. Subsequent binding of CPPs is likely to occur in the minor groove and later on bind randomly, to siRNA or previously bound CPPs, through hydrophobic interactions. However, hydrophobic CPPs do not show this binding pattern. Ultimately binding yields a positively charged nanoparticle capable of noninvasive cellular import of therapeutic molecules.
\end{abstract}

\section{Introduction}

Recently, therapeutics have shown a vast diversification from small molecule drugs. Peptide and nucleic acid based therapeutics are among these alternatives and have been developed tremendously, to the point of clinical trials [1-3]. Short interfering RNA (siRNA) is among the therapeutics which have captured the interest of researchers [1,4-7]. Once introduced into cells these oligonucleotides drive the RNA interference (RNAi) process [8], in which the expression of a target protein is suppressed by stimulating the specific degradation of messenger RNA. This mechanism leads to high specificity and large number of possible targets.

Major hurdles in the deployment of siRNA therapeutics are the low intracellular stability and low cellular uptake $[9,10]$. A general cause of lower cellular uptake of gene therapeutics is the poor penetration through the cell membrane, which is efficient in regulating the internalization of foreign substances. Numerous carriers and drug delivery systems have been developed [11-14], including viral delivery, electroporation [15], and encapsulation and association of drugs with lipids [16], peptides [17-19], polymers [20], nanotubes [21], liposomes [22], micelles [23], and dendrimers [24].

This paper focuses on cell penetrating peptides (CPPs) with respect to their delivery of siRNA to cells through the use of computer modeling and simulation. We studied the structural features of seventeen CPPs and their capacity to form noncovalent complexes with siRNA.

1.1. siRNA and the RNA Interference (RNAi) Pathway. Unlike most RNAs, siRNA is a double strand (ds) RNA with 1923 base pairs with characteristic $3^{\prime}$ overhangs (see Figure 1 ). Having overhangs facilitates the recognition by the enzymatic 

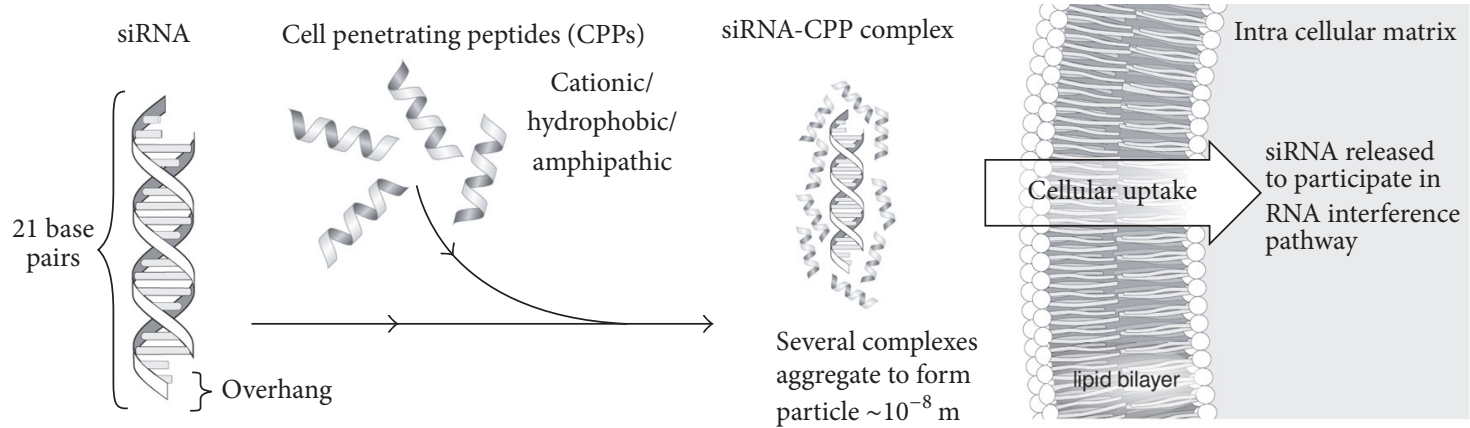

FIGURE 1: Cell penetrating peptides can bind with siRNA to form dense complexes. Several of those complexes can aggregate and translocate through the cell membrane.

machinery of RNAi [4]. Usually, the siRNA is generated by Rnase III, the "Dicer" enzyme which cleaves long dsRNA into siRNA. The siRNAs can then bind to the RISC (RNAinduced silencing complex). Within the RISC, the siRNA is unwound and the sense strand is removed for degradation by nucleases present in the cell. The antisense strand specifically targets certain sequences of mRNA and directs them to the RISC. Then, it anneals with the complementary base pair. Finally, a rapid degradation of the target mRNA takes place, and consequently decreased protein expression results.

For siRNA to become a viable therapeutic, enzyme and environmental degradation have to be overcome with a proper delivery system. Therefore, extensive attention has been given to noninvasive peptide based delivery of siRNA into mammalian cells.

1.2. Cell Penetrating Peptides (CPPs). Cell penetrating peptides are a distinct class of small peptidic molecules, having a special ability to trigger the movement of molecules across the cell membrane. CPPs have been shown to penetrate the cell membrane as well as mitochondrial and nuclear membranes without damaging them [25]. Known CPPs share many structural features and physical properties. Firstly, they are all water soluble. Secondly, CPPs are relatively small in size, not having more than 35 amino acid residues. Moreover, the cytotoxicities of these molecules are very low [26]. There is no unique classification for CPPs. They can be categorized according to their origin, according to their ability to link with the cargo, and according to their structure. Classification of CPPs by their structure separates peptides as (i) cationic CPPs, (ii) amphipathic CPPs, and (iii) hydrophobic CPPs.

1.3. CPP-siRNA Complexes. CPPs of all three classes have been used for the delivery of siRNA with success. Here several peptides adsorb on the surface of siRNA. Interactions driving peptide adsorption can be nucleotide specific, or nonspecific. Protein-nucleic acid complexation is primarily governed by electrostatic interactions where the negatively charged backbone of the polynucleotide is the key acceptor of charged species.

The secondary structure and shape complementarity also plays a role in the binding of peptides to nucleotides.

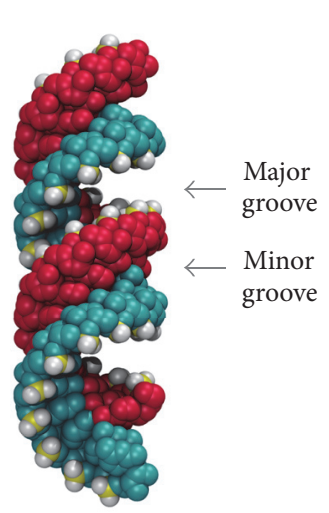

A-form siRNA

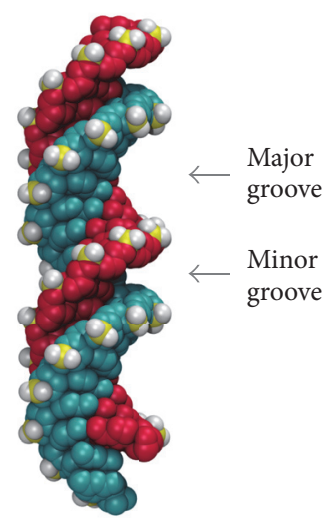

B-form siRNA
FIGURE 2: Structural differences of major groove and minor groove of A-form and B-form of siRNA (glyceraldehyde-3-phosphate dehydrogenase downregulating siRNA is represented here).

Previously Schleif et al. speculated that helical peptides would show high binding affinities with double stranded RNA. The authors suggested that when the alpha-helix CPP is tilted, it can fit into the major groove of the dsRNA via hydrogen bonds and van der Waals interactions [27-29]. Furthermore, nitrogen base pairs which are exposed grooves of the RNA can become involved in sequence specific $\mathrm{H}$ bonds $[28,30]$.

It follows that the conformation of dsRNA influences the binding of peptides due to the presence of $2^{\prime}-\mathrm{OH}$ groups in RNA; it naturally exists mostly in the thermodynamically stable A-form [31]. Thus DNA or B-formed RNA (see Figure 2) will not trigger the RNAi pathway. However, it is important to look into both conformations of RNA to get a broader idea about binding of CPPs to comprehend if there is a significant difference in between the bindings and thereby analyze any alternative means to fine-tune the siRNA-CPP complex.

As a result of inherent peptide-nucleic acid interaction, complexation of siRNA with multiple peptides usually occurs. This leads to the formation of complex, with a net positive charge. Further aggregation of these complexes forms dense nanoparticles, with a size of $10^{2} \mathrm{~nm}$ that may be internalized via endosomes [12, 32, 33]. This formation of a positively charged nanoparticle is important for translocation 
into the cell membrane and delivering the therapeutics. Here, our main focus is to study the formation of the positively charged complex which is the initial step of internalization [34].

In this research, we study the initial binding of CPPs to siRNA and focus on the interactions governing the complexation. To achieve a complete understanding about the binding of CPPs to siRNA, we performed docking calculations for 17 different peptides from all the structural classes. Calculations were performed for binding of CPPs for both A- and Bforms of the same GAPDH siRNA (see Figure 2). This siRNA downregulates the translation of glyceraldehyde-3phosphate dehydrogenase (GAPDH) enzyme. GAPDH catalyses the conversion of glyceraldehyde-3-phosphate to Dglycerate 1,3-bisphosphate in the glycolytic breakdown of glucose. Furthermore, best scored CPPs from three categories were docked with another different siRNA, HPV si16E6, to confirm the binding pattern. To generalize the findings of the study, siRNA downregulating Human Papillomavirus (type 16) E6 oncoprotein, si16E6, was used for comparison.

\section{Methodology}

2.1. Generating Coordinates of siRNA. For the study, two siRNA molecules were arbitrarily chosen, namely, the GAPDH and si16E6. Ideal A- and B-forms of helical structure of the glyceraldehyde-3-phosphate dehydrogenase (GAPDH), with a sense strand $5^{\prime}$-GACGUAAACGGCCACAAGUUC- ${ }^{\prime}$ and antisense strand of $5^{\prime}$-ACUUGUGGCCGUUUACGUCGC$3^{\prime}$, were generated using the make-na online server (NAB [35], Nucleic Acid Builder based application with Generalized Born, Poisson-Boltzmann, or 3D-RISM implicit solvent models). Ideal A-form of sil6E6 with sense strand $5^{\prime}$-GCAACAGUUACUGCGACGUUU- $3^{\prime}$ and an antisense strand of $5^{\prime}$-ACGUCGCAGUAACUGUUGCUU- $3^{\prime}$ was also generated similarly with the same procedure. Once created, the stability of siRNA in aqueous medium was checked through molecular dynamics simulations using explicit (TIP3P) water at physiological temperature $(310 \mathrm{~K})$, for $24 \mathrm{~ns}$ using NAMD code and CHARMM v27 force field with time step of 2 fs/ts. The particle-particle mesh Ewald method was used for the long-ranged Coulombic interactions. A cutoff of $12 \AA$ was used for the van der Waals interactions and shortranged Coulombic interactions. Neighbor atom pair-lists were truncated at a distance of $13.5 \AA$ and were updated every 10 time steps. RATTLE/SHAKE algorithms were used to constrain the bond length of the hydrogen-heavy atom bonds.

2.2. Generating Coordinates of Cell Penetrating Peptides. Generation and structure prediction of CPPs were carried out using PEP-FOLD [36-38] 2011 online server. All peptides were subjected to energy minimization via the NAMD code [39] and minimized structures were used for further calculations. For the minimization, the CHARMM v27 force field was used with the conjugate gradient minimization scheme.
2.3. Molecular Docking Calculations. Docking calculations were performed by the ClusPro $[40,41]$ online server with default (balanced weight) configurations. For docking simulations of CPP with siRNA, the siRNA was taken as the receptor while the CPP was regarded as the ligand. Docking calculations were submitted and the resulting output with minimum energy and highest clusters was taken for further calculations. These structures were minimized as before using the NAMD code [39] and GROMACS [42] v5 with the CHARMM [43] v27 force field and used for subsequent docking calculations. In the next step, the CPPsiRNA complex was taken as the receptor, and another CPP was taken as the ligand. This process was carried out up to 30 CPPs and the generated binding scores and coordinates were recorded. This docking process was carried out for GAPDH (A- and B-forms) and HPV sil6E6 (A-forms). For A-form of GAPDH minimization was done using NAMD code and the rest were carried out in GROMACS version 5. From the amphipathic, cationic, and hydrophobic classes, the three best scoring CPPs were used and docking studies carried out. However, for HPV sil6E6, docking was carried out for three best scoring CPPs in three groups.

A similar procedure was used to evaluate the dimerization docking energy scores, but here only two peptides were considered.

2.4. ClusPro Scoring Function. The energy function used in ClusPro represents shape complementarity, electrostatic, and desolvation contributions [70].

$$
\begin{aligned}
E & =E_{\text {shape }}+\omega_{2} E_{\text {elec }}+\omega_{3} E_{\text {pair }}, \\
E_{\text {shape }} & =E_{\text {attr }}+\omega_{1} E_{\text {rep }},
\end{aligned}
$$

where $E$ denotes the docking score, while $E_{\text {shape }}, E_{\text {elec }}$, and $E_{\text {pair }}$ denote shape complementarity, electrostatic, and desolvation contributions, respectively. The shape complementarity term $E_{\text {shape }}$ accounts for both attractive $\left(E_{\text {attr }}\right)$ and repulsive $\left(E_{\text {rep }}\right)$ interactions. ClusPro provides four variations of energy functions by varying $\omega_{1}, \omega_{2}$, and $\omega_{3}$ coefficients. Docking scores reported use the "balanced" energy function, where the weightage of the components is

$$
E=0.40 E_{\text {rep }}-0.40 E_{\text {att }}+600 E_{\text {elec }}+1.00 E_{\text {DARS }} \text {. }
$$

Both attraction and repulsion terms were considered in the energy function with the same weight. Electrostatic interactions were considered between the two proteins surrounded by solvent using simplified Generalized Born (GB) theory, with constant radii. More importantly, ClusPro introduces new structure-based, pairwise intermolecular potential DARS (Decoys as the Reference State). Detailed information on these terms can be found in Kozakov et al. (2006).

2.5. Explicit Solvent Molecular Dynamics Simulations. Both NAMD and GROMACS code were used for molecular dynamics simulations with a time step of $2 \mathrm{fs} / \mathrm{ts}$. All the simulations of involving GAPDH B-form siRNA were carried out in NAMD, while simulations involving GAPDH Aform siRNA and siR16E6 siRNA were run in GROMACS. 
TABLE 1: List of CPPs included in the study.

\begin{tabular}{|c|c|c|c|c|}
\hline CPP type & CPP name & $\begin{array}{l}\text { Amino acid sequence (underlined } \\
\text { residues are positively charged) }\end{array}$ & Residue count & $\begin{array}{l}\text { Nominal charge } \\
\text { (charge per } \\
\text { residue) }\end{array}$ \\
\hline \multirow{5}{*}{$\begin{array}{l}\text { Cationic cell } \\
\text { penetrating } \\
\text { peptides }\end{array}$} & Penetratin $[44,45]$ & $\underline{\text { RQIKIWFQNRRMKWKKK }}$ & 16 & $+7(0.44)$ \\
\hline & HIV-TAT $(47-57)[46,47]$ & YGRKKRRQRRR & 11 & $+8(0.72)$ \\
\hline & $\mathrm{R} 10[48,49]$ & RRRRRRRRRR & 10 & $+10(1.00)$ \\
\hline & CCMV Gag (7-25) [49-51] & KLTRAQRRAAARKNKRNTRGC & 21 & $+9(0.43)$ \\
\hline & $\begin{array}{l}\text { Chimeric dermaseptin S4 and } \\
\text { SV40 'S413-PV' }[11,34]\end{array}$ & ALW $\underline{K T L L K K V L K A P K K K R K V C}$ & 21 & $+9(0.43)$ \\
\hline \multirow{6}{*}{$\begin{array}{l}\text { Amphipathic cell } \\
\text { penetrating } \\
\text { peptides }\end{array}$} & Transportan $[52]$ & GWTLNSAGYLLGKINLKALAALAKKIL & 27 & $+4(0.15)$ \\
\hline & $\begin{array}{l}\text { pVEC (vascular endothelial } \\
\text { cadherin) }[53-56]\end{array}$ & LLIILRRRIRKQAHAHS $\underline{\underline{K}}$ & 18 & $+6(0.33)$ \\
\hline & MPG $[57,58]$ & GALFLGFLGAAGSTMGAWSQPKKKRKV & 27 & $+5(0.16)$ \\
\hline & CADY $[59,60]$ & GLWRALWRLLRSLWRLLWRA & 20 & $+5(0.25)$ \\
\hline & sC18 [61] & GLRKRLRKFRNKIKEK & 16 & $+8(0.50)$ \\
\hline & C6 [62] & RLLRLLLRLWRRLLRLLR & 18 & $+7(0.39)$ \\
\hline \multirow{6}{*}{$\begin{array}{l}\text { Hydrophobic cell } \\
\text { penetrating } \\
\text { peptides }\end{array}$} & $\begin{array}{l}\text { K-FGF (Kaposi's sarcoma } \\
\text { fibroblast growth factor) [63] }\end{array}$ & AAVALLPAVLLALLAP & 16 & $0(0.00)$ \\
\hline & Integrin $\beta 3$-fragment $[64,65]$ & VTVLAGALAGVGVG & 14 & $0(0.00)$ \\
\hline & $\begin{array}{l}\text { Hepatitis B virus translocation } \\
\text { motif }[66]\end{array}$ & PLSSIFSRIG $\underline{D P}$ & 12 & $0(0.00)$ \\
\hline & Grb2 $\left(\mathrm{SH}_{2}\right.$ domain $)[67]$ & AAVLLPVLLAAP & 12 & $0(0.00)$ \\
\hline & $\begin{array}{l}\text { Fusion sequence HIV-1 } \\
\text { gp41(1-23) }[46,68]\end{array}$ & GALFLGFLGAAGSTMGA & 17 & $0(0.00)$ \\
\hline & C105Y [69] & CSIPPEVKKFNKEPFVYLI & 17 & $+1(0.06)$ \\
\hline
\end{tabular}

To maintain the same environment CHARMM v27 force field was used along with a cutoff of $12 \AA$ for the van der Waals interactions and short-ranged Coulombic interactions, while the particle-particle mesh Ewald method was used for the long-ranged Coulombic interactions. Neighbor atom pair-lists were truncated at a distance of $13.5 \AA$ and were updated every 10 time steps. CHARMM compatible TIP3P explicit waters were used for all simulations. To constrain the bond length of the hydrogen-heavy atom bonds the LINCS algorithm and RATTLE/SHAKE algorithms were used in GROMACS and NAMD, respectively.

\section{Results and Discussion}

In this study, we investigated the binding of cell penetrating peptides (CPPs) onto short interfering RNA (siRNA). Since this delivery route is under vigorous development, structural features of peptides which increase the effectivity of siRNA delivery are of prime interest. Specifically, discovering features which enhance binding of peptides to siRNA or enhance the cellular uptake would be advantageous in future design of de novo peptides.

3.1. Binding of CPPs to siRNA. As described in the methodology, docking calculations were performed to investigate the binding of CPPs to the siRNA, particularly as a function of
siRNA : CPP ratio. Calculations were carried out through the ClusPro server, which uses a rigid body docking algorithm in generating the favorable orientations of docking, based on clustering. Docking scores are an approximate analog to binding free energies calculated by more thorough computational techniques such as molecular dynamics simulations. However, due to the expense of free energy calculations, and the number of different binding energies which are required to exhaustively analyze this problem, we have used docking as a realistic alternative. Furthermore, we focus more on the molecular geometries produced, and trends in the binding scores are observed.

To generalize our results, cell penetrating peptides over a wide range of physicochemical characters were studied: cationic, amphipathic, and hydrophobic. Details on the CPP used in the study are given in Table 1, including the amino acid sequences, trivial name, nominal charge, and nominal charge per residue.

The complete set of binding scores obtained by docking calculated are available in the supplementary data in Supplementary Material available online at https://doi.org/10.1155/ 2017/1059216. However, since we are more concerned about the trends in the sequential binding events rather than the absolute scores, a concise graphical representation of docking results is shown in Figures 3 and 4.

From the binding energies (shown in Figures 3 and 4) the general trend is apparent; initially the binding of CPP onto 


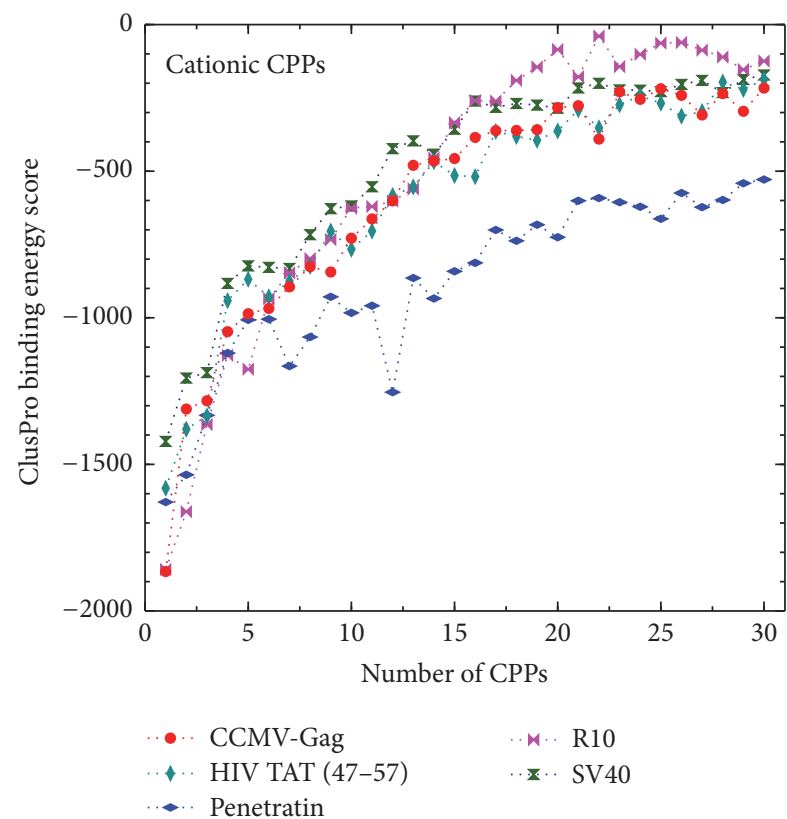

(a)

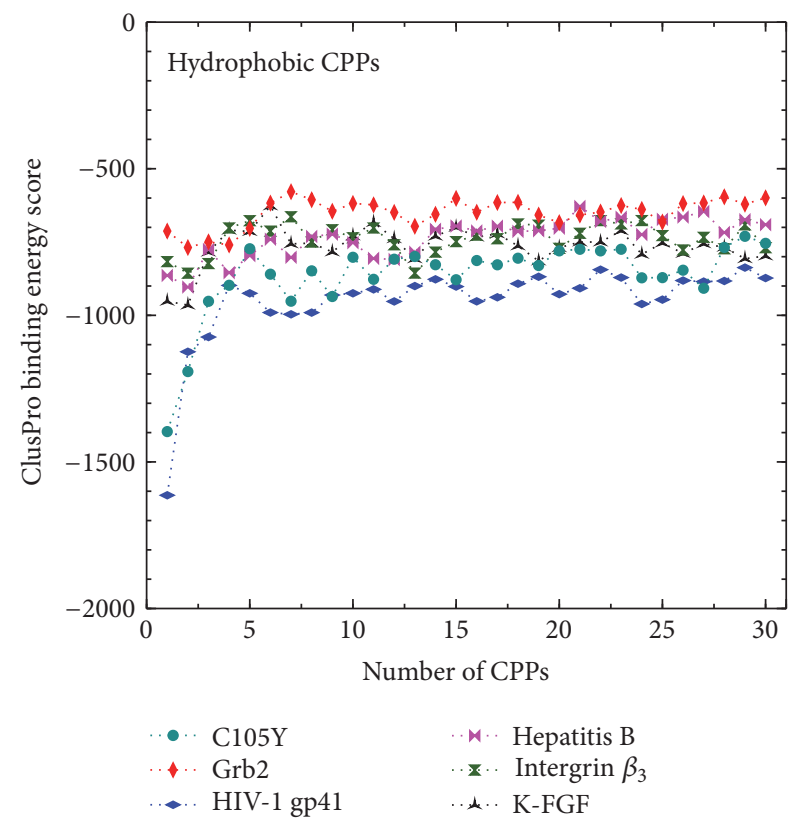

(b)

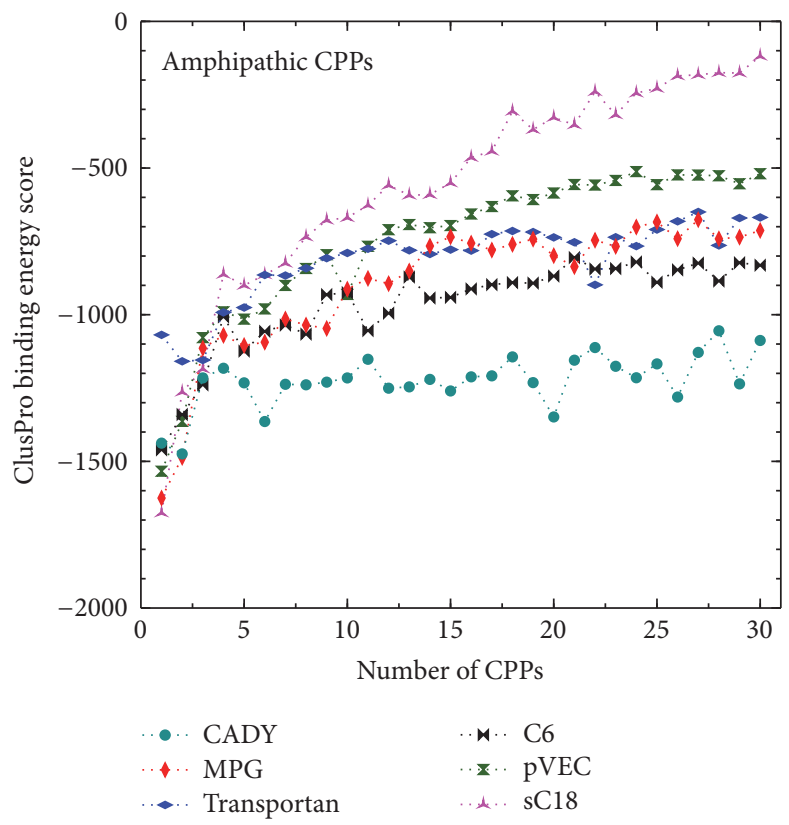

(c)

FIGURE 3: The variation in binding scores for the complexation of a successive number of peptides (see Table 1) with GAPDH (A-form).

the siRNA is the most favorable, while the magnitude of the binding scores generally decreases with the number of CPPs complexed with the siRNA. To illustrate the trends specific to each class of peptide, we will discuss them separately.

Cationic CPPs. Cationic peptides are, by nature, rich in positively charged residues, mostly arginine and lysine. For example, R10 consists of only arginine. As a result of having these residues present, the number of possible intramolecular hydrogen bonds is decreased [71]. Therefore, the secondary structure presents predominantly coils and tubes, not helices
[72]. The same phenomena can be seen with HIV-TAT (4757), which is predicted to have a random coil structure.

All cationic peptides have a nominal charge between +7 and +10 . Due to Coulombic attraction between the positively charged CPP and the negatively charged siRNA, peptides with higher positive charge density would bind more strongly. This is also supported by the binding scores for the complexation of the cationic peptides with siRNA (see Figures 3 and 4). Among the cationic peptides, R10 shows the maximum charge density (nominal charge density of 1.00) and consequently it displays relatively high affinity for the 


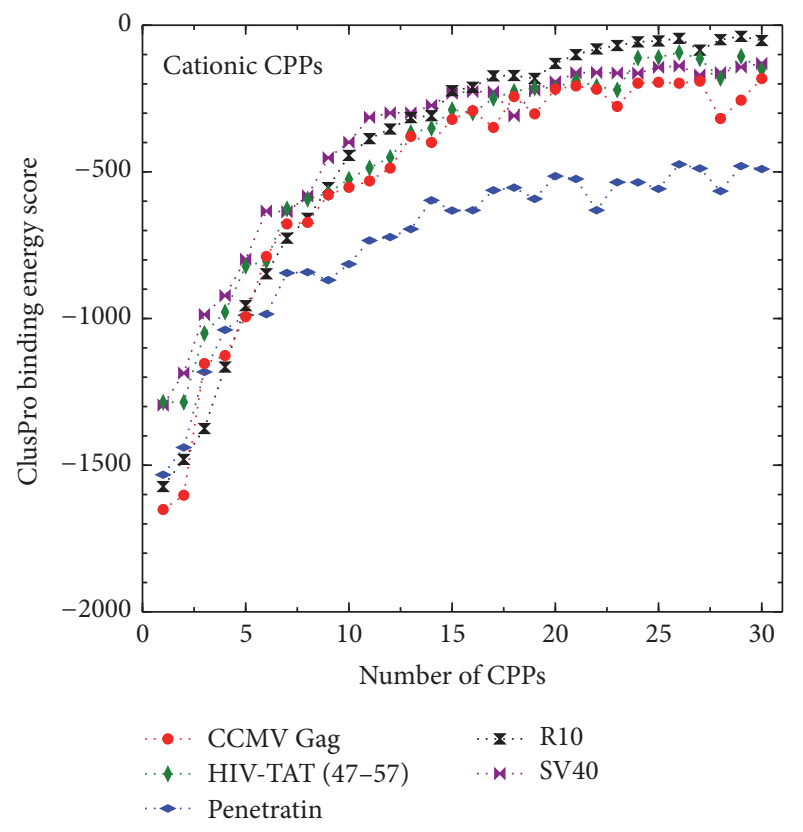

(a)

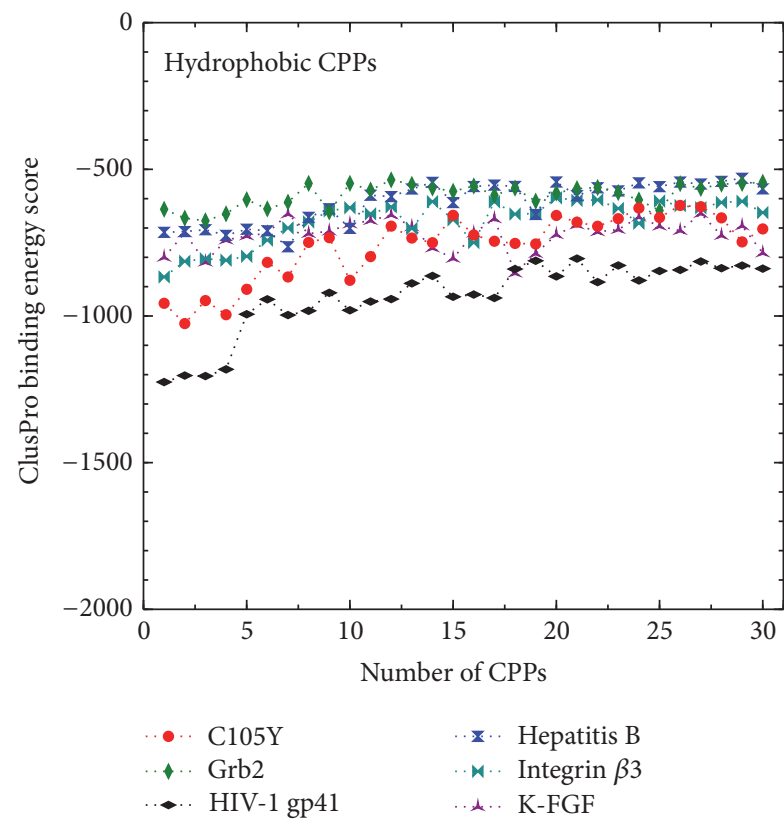

(b)

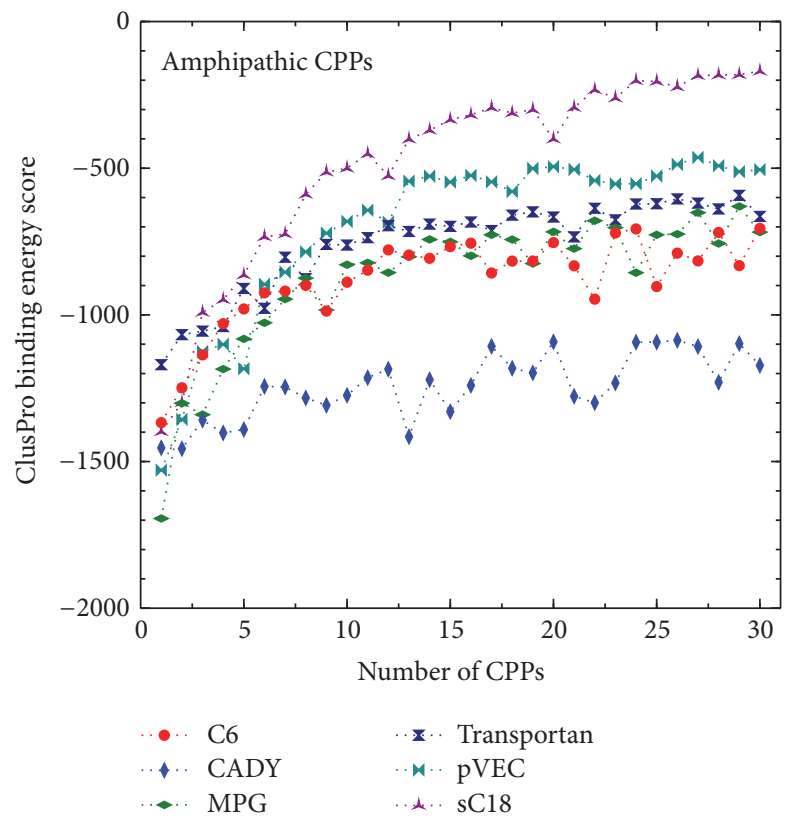

(c)

FIGURE 4: The variation in binding scores for the complexation of a successive number of peptides (see Table 1) with GAPDH (B-form).

initial binding of peptides to the siRNA. Complexation driven by Coulombic interactions would be expected to decrease in magnitude due to progressively diminishing attractive force. This is illustrated through R10, which shows a drastic and monotonous lowering (in magnitude) of binding energy score at higher CPP : siRNA ratios, plateauing at around scores of -100 (Figures 3(a) and 4(a)). This trend is observed to a lesser extent in all of the cationic CPPs. Among them the highest gradient of binding energy score and largest initial binding energy score is displayed in CCMV-Gag and R10 with both forms of siRNA. Considering all cationic CPPs, it can be seen that Penetratin has low binding scores at high $\mathrm{CPP}$ : siRNA ratios. It stabilizes after binding of $\sim 15$ th $\mathrm{CPP}$ at $\sim-700$ binding score.

When inspecting the orientation and placement of the cationic CPP on the siRNA (in both A- and B-forms), in all considered cases the initial CPP complexation occurs at the major groove of the siRNA (see Figures 5A1 and 5B1). However, unexpectedly, this is seen for both helical and random coil peptides. After the addition of a couple (two to three) of CPPs, the major groove is filled, and peptides preferentially bind to the minor groove of the siRNA, as 


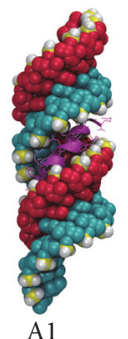

A1

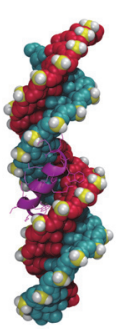

B1

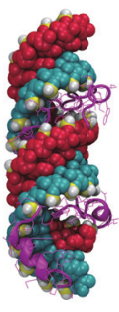

A2

(a)

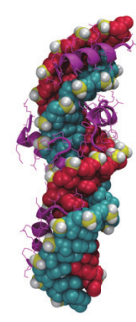

B2
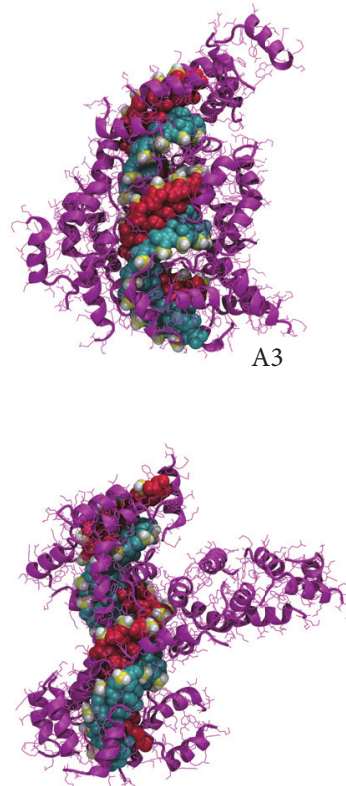

B3

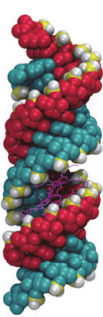

A1

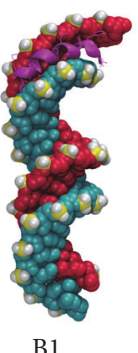

$\mathrm{B} 1$

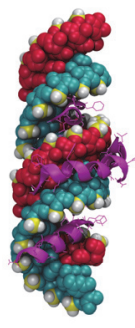

A2

(a)

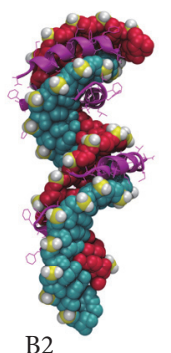

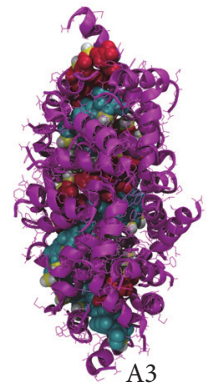

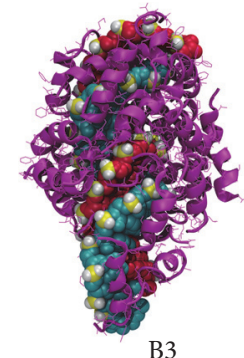

(b)

(b)

FIgURE 6: Predicted structures of CPP-GAPDH ((a) A-form; (b) Bform) complex from docking calculations. Pictures show the HIV-1 gp41 (1-23) peptide representing the hydrophobic class of CPPs. The peptide to siRNA ratios are 1:1 (left), 5:1 (center), and 30:1 (right), respectively.

the major groove or the minor groove. Figures $6 \mathrm{~B} 1$ and $6 \mathrm{~B} 2$ show the first two HIV-1 gp41 (1-23) peptides binding to the minor groove of the siRNA. However, in the A-form, HIV-1 gp41 (1-23) has randomly bound to the major groove, resulting in a significantly low binding energy score. Upon further binding of peptides, they show no orientational bias and complex in a random manner. Furthermore, because of the hydrophobic composition of the peptides, the peptidesiRNA complex arranges to minimize the surface area, as evidenced by the low solvent SASA values that were observed (see supplementary data). This leads to the formation of a dense, tightly packed peptide-siRNA particle (Figures 6A3 and 6B3).

Amphipathic CPPs. These peptides exhibit both hydrophobic and hydrophilic behavior and/or regions in their structure. Usually, this capability comes with the presence of lysine as a component in the peptide [73]. All amphipathic peptides considered in the study are rich in lysine and have nominal charges between +4 and +8 . Having both the positive charge of the cationic class and the nonpolar groups characterizing the hydrophobic peptides, this class shows the advantages of both. They show the initially strong binding of cationic peptides, a gradual decline, and finally plateauing (see Figures 3 and 4). As with the cationic CPPs, the amphipathic CPPs also bind initially to the major groove (Figures 7Al and 7B1) with negative binding energy scores ranging from -1200 to -1800 . However, when the number of CPPs is increased, binding energies rise sharply within 1-5 CPPs and

becomes steady. Due to the presence of nonpolar groups, not follow specific orientations in binding to siRNA. Initially the hydrophobic peptides were predicted to bind to either 


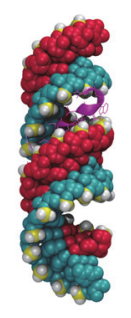

A1

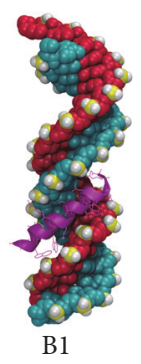

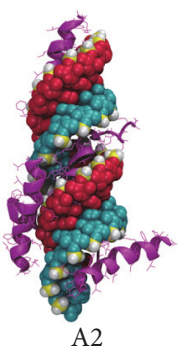

(a)

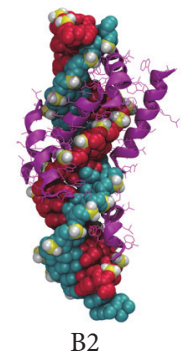

(b)
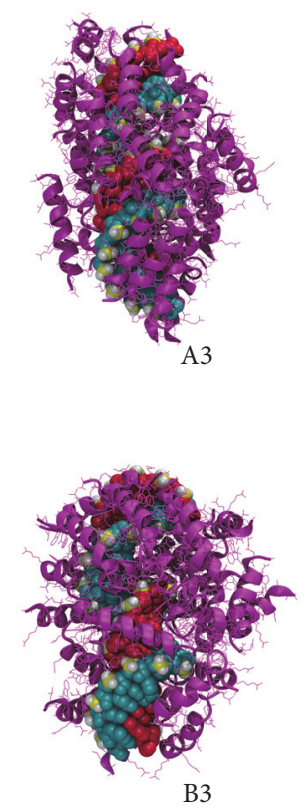

B3
FIgURE 7: Predicted structures of CPP-GAPDH ((a) A-form; (b) B-form) complex from docking calculations. Pictures show the CADY peptide representing the amphipathic class of CPPs. The peptide to siRNA ratios are 1:1 (left), 5:1 (center), and 30:1 (right), respectively.

the hydrophobic effect allows the peptides to bind those peptides already present in the complex, resulting in relatively large binding energies at high CPP : siRNA ratios, compared to cationic peptides (see Figures 3(a), 4(a), 3(c), and 4(c)). Surprisingly, there is no clear trend between the predicted secondary structure (which is used in the docking) and the binding scores generated, where helical, beta-sheet, and random coil structures all exhibited similar binding scores. From the amphipathic peptides, sC18 and CADY indicate slight deviations. sC18 shows comparatively larger elevation of binding energies; CADY shows less. This indicates a favorable complexation of CADY and less favorable complexation of $\mathrm{sC} 18$ with siRNA.

Considering the results collectively, cell penetrating peptides with helical structures show higher binding affinity to siRNA such as CADY, C6, and sequence HIV-1 gp41 (1-23). By nature, most relatively small ( $<40$ residue) peptides tend to arrange in helical structures; helices maximize intramolecular hydrogen bonding and provide better distribution of residues throughout the structure, which enables higher interacting power with the external environment. Spatial arrangement of cell penetrating peptides also provides less steric hindrance to bind to the major or the minor groove. Furthermore, having larger side chains on the peptide discourages the binding, thus showing higher binding energies. Particularly, peptides containing tryptophan and tyrosine exhibit slightly attenuated binding.

Since almost all siRNAs show identical structures, the same binding pattern was observed as shown in Figure 8. However, due to structural differences in major grooves and minor grooves, slight lowering of binding energy was observed in A-forms (for both GAPDH and HPV-si16E6).

Considering the results, the following stages of peptide binding can be extracted. (1) Initially electrostatic and shape complementarity drive the binding of cell penetrating peptides into the major groove of siRNA, where the maximum salt bridges may be formed. At this stage positive charge on the peptide is beneficial. Due to the small size of siRNA, only 2-3 CPPs can be accommodated into the major groove. (2) Subsequent peptides tend to bind to minor groove of siRNA while some get arranged perpendicular to the siRNA. Increased charge on the peptide tends to favor binding of the peptides to the minor groove. However, with the increasing number of peptides, more peptide-peptide interactions are observed. With further increase of the CPP to siRNA ratio, the peptides are observed to bind either onto the siRNA or to previously bound CPPs. Here, the competition of the peptidesiRNA and the peptide-peptide interaction play a major role. (3) Finally, once the surface charge on the siRNA has been screened, and a complete coating of the siRNA has taken place, further aggregation of peptides may occur, where the size of the siRNA-peptide complex is increased.

The docking scores for binding CPP initially to the Aand B-form show slight differences. The main reason that can be identified is the shape of the major groove of siRNA. The A-form helix is more coiled than the B-form helix, creating narrow, deep major groove and shallow, wide minor groove. Thus CPPs can interact with deeper major groove and thereby create a stable complex. This phenomenon is often evident in cationic CPPs since the positive charge drives Coulombic attraction with negative charges in nucleotide. Moreover, whenever a CPP is bound to major groove, it shows negatively larger binding score regardless of the type of CPP. One such example is initial binding of HIVlgp41 and C105Y to A-form of siRNA which is significantly lower than that of others since they are bound to major groove.

3.2. Aggregation and General Outlook. It goes without saying that the aggregation behavior of the peptides is essential information. To better evaluate this quantity, docking simulations of CPP dimerization were also carried out. Although approximate, the resultant scores agree with the expected trend; cationic peptides showed the lowest binding, while the amphipathic and hydrophobic peptides showed more favorable binding scores (see supplementary information for values). The balance between the peptide-siRNA and peptide-peptide interactions also affects the formation of nanoparticles and release of the therapeutic molecule(s) to the cytoplasm. Having a highly stable complex might be problematic when releasing the therapeutic molecule. On the other hand, if peptide-peptide interactions are too high, proteins will aggregate prior to complexing with siRNA. The size and nature of the aggregate are also important in the cell membrane translocation of siRNA-CPP complexes.

Experimental results suggest that aggregates of several siRNA-CPP complexes will interact with each other and produce larger particles (which reside in the $10^{2} \mathrm{~nm}$ size scale), which have the ability to overcome the cell membrane barrier. 


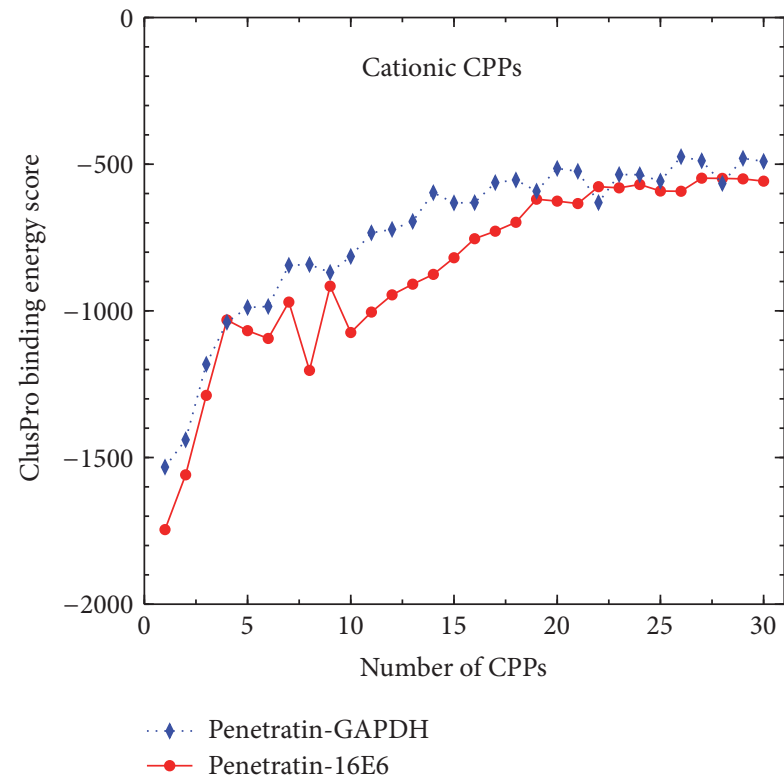

(a)

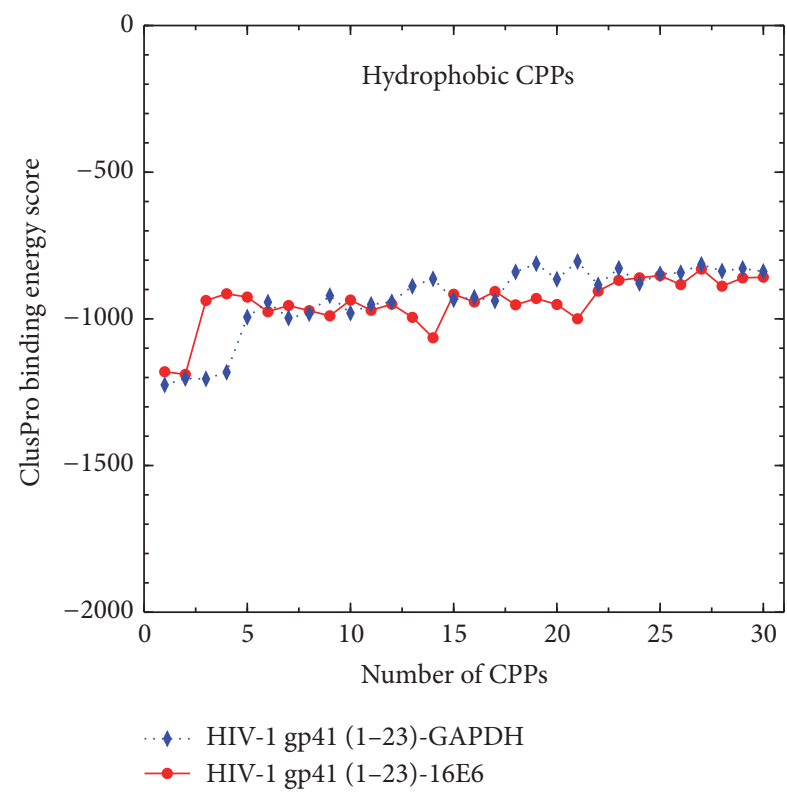

(b)

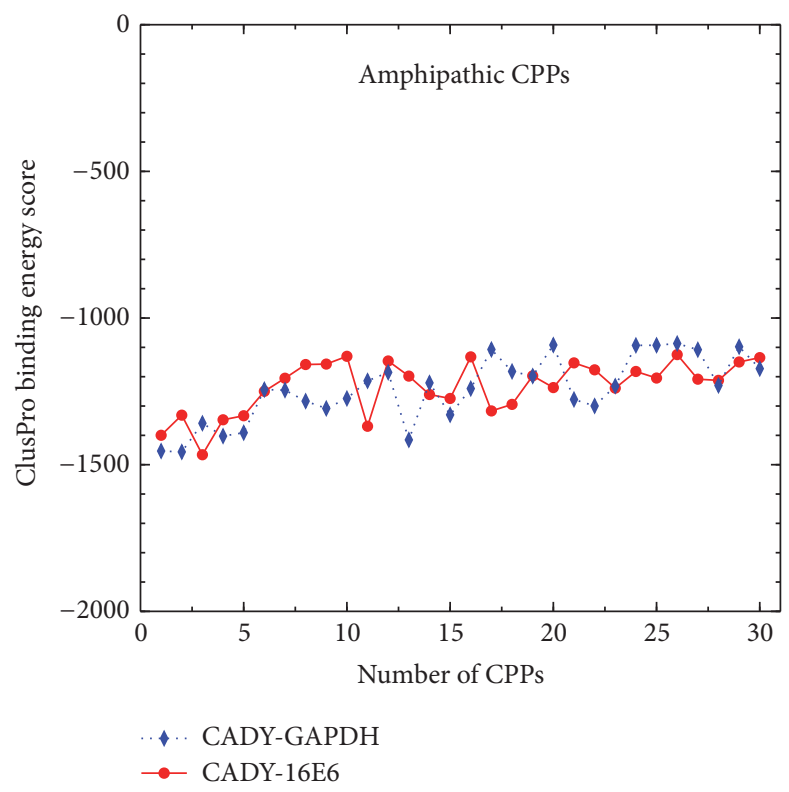

(c)

FIGURE 8: The variation in binding scores for the complexation of a successive number of cationic, hydrophobic, and amphipathic peptides with A-form of HPV-sil6E6 and GAPDH siRNAs.

Here, the siRNA: CPP 1:30 complexes are $10 \mathrm{~nm}$ in size. However, among the mentioned three categories, a significant variation in the SASA can be seen (see supplementary information). For the cationic peptides, for siRNA: CPP of $1: 30$, the SASA values are in the range of $402-550 \mathrm{~nm}^{2}$, while for the hydrophobic and amphipathic peptide the ranges were $185-265 \mathrm{~nm}^{2}$ and $395-472 \mathrm{~nm}^{2}$, respectively. The size and the physicochemical nature of the exposed surface and the size of final multicomplex nanoparticle are known to have a large impact on the internalization. However, we cannot predict the final size of the aggregates using the techniques used in this research but only suggest that the highly charged complexes are unlikely to aggregate in large numbers due to the unfavorable charge and solvation effects.

The structures and associated binding scores calculated here should only be taken as representative. Although the docking algorithm used samples over many of the possible locations and orientations of binding, only limited flexibility is allowed for the peptide when binding. Therefore, firstly the initial predicted structure plays a large role in the predictions, and secondly the process does not sample the free energy of the binding processes with the correct weights. So there will be a significant error in the associated results. Given this limitation, we have taken care not to use the absolute binding 
scores in interpreting the results and use only the relative differences between the peptides, and the variation in binding scores for a single type of peptide, to minimize systematic errors. However, due to the sensitivity of peptide structure to environmental conditions, this is a large source of uncertainty in the study. We hope future studies of chosen peptides and structures may allow more quantitative information about the binding process, which will allow future experimentalists and peptide designers to further progress in this field. Because much of the mechanisms involved in this delivery mechanism are not fully understood, our knowledge in properties which enhance cellular uptake is largely empirical. More pedagogical investigation of each step in the pathway of complexation, internalization, release, and metabolism is required to fully understand and manipulate this attractive technology.

\section{Competing Interests}

The authors declare that they have no competing interests.

\section{References}

[1] H. Borna, S. Imani, M. Iman, and S. Azimzadeh Jamalkandi, "Therapeutic face of RNAi: in vivo challenges," Expert Opinion on Biological Therapy, vol. 15, no. 2, pp. 269-285, 2015.

[2] J. Tabernero, G. I. Shapiro, P. M. LoRusso et al., "First-inhumans trial of an RNA interference therapeutic targeting VEGF and KSP in cancer patients with liver involvement," Cancer Discovery, vol. 3, no. 4, pp. 406-417, 2013.

[3] B. L. Davidson and P. B. McCray, "Current prospects for RNA interference-based therapies," Nature Reviews Genetics, vol. 12, no. 5, pp. 329-340, 2011.

[4] L. Aagaard and J. J. Rossi, "RNAi therapeutics: principles, prospects and challenges," Advanced Drug Delivery Reviews, vol. 59, no. 2-3, pp. 75-86, 2007.

[5] D. Cejka, D. Losert, and V. Wacheck, "Short interfering RNA (siRNA): tool or therapeutic?" Clinical Science, vol. 110, no. 1, pp. 47-58, 2006.

[6] A. Luchnik, "DNA conformational transitions induced by supercoiling control transcription in chromatin," Gene Regulation and Systems Biology, vol. 8, pp. 89-96, 2014.

[7] H. Yin, R. L. Kanasty, A. A. Eltoukhy, A. J. Vegas, J. R. Dorkin, and D. G. Anderson, "Non-viral vectors for gene-based therapy," Nature Reviews Genetics, vol. 15, no. 8, pp. 541-555, 2014.

[8] P. D. Zamore, "RNA interference: listening to the sound of silence," Nature Structural Biology, vol. 8, no. 9, pp. 746-750, 2001.

[9] C. Foerg and H. P. Merkle, "On the biomedical promise of cell penetrating peptides: limits versus prospects," Journal of Pharmaceutical Sciences, vol. 97, no. 1, pp. 144-162, 2008.

[10] Y.-L. Yang, W.-T. Chang, and Y.-W. Shih, "Gene therapy using RNAi," in Gene Therapy-Developments and Future Perspectives, InTech, Rijeka, Croatia, 2011.

[11] S. Trabulo, A. L. Cardoso, M. Mano, and M. C. P. de Lima, "Cell-penetrating peptides-mechanisms of cellular uptake and generation of delivery systems," Pharmaceuticals, vol. 3, no. 4, pp. 961-993, 2010.

[12] T. Lehto, K. Kurrikoff, and Ü. Langel, "Cell-penetrating peptides for the delivery of nucleic acids," Expert Opinion on Drug Delivery, vol. 9, no. 7, pp. 823-836, 2012.
[13] I. R. de Figueiredo, J. M. Freire, L. Flores, A. S. Veiga, and M. A. R. B. Castanho, "Cell-penetrating peptides: a tool for effective delivery in gene-targeted therapies," IUBMB Life, vol. 66, no. 3, pp. 182-194, 2014.

[14] D. N. Karunaratne, M. Jafari, R. J. K. U. Ranatunga, and A. Siriwardhana, "Natural carriers for siRNA delivery," Current Pharmaceutical Design, vol. 21, no. 31, pp. 4529-4540, 2015.

[15] E. Neumann, M. Schaefer-Ridder, Y. Wang, and P. H. Hofschneider, "Gene transfer into mouse lyoma cells by electroporation in high electric fields," EMBO Journal, vol. 1, no. 7, pp. 841-845, 1982.

[16] A. Akinc, A. Zumbuehl, M. Goldberg et al., "A combinatorial library of lipid-like materials for delivery of RNAi therapeutics," Nature Biotechnology, vol. 26, no. 5, pp. 561-569, 2008.

[17] C. Foged and H. M. Nielsen, "Cell-penetrating peptides for drug delivery across membrane barriers," Expert Opinion on Drug Delivery, vol. 5, no. 1, pp. 105-117, 2008.

[18] F. Mussbach, M. Franke, A. Zoch, B. Schaefer, and S. Reissmann, "Transduction of peptides and proteins into live cells by cell penetrating peptides," Journal of Cellular Biochemistry, vol. 112, no. 12, pp. 3824-3833, 2011.

[19] J. M. Freire, A. S. Veiga, I. Rego de Figueiredo et al., "Nucleic acid delivery by cell penetrating peptides derived from dengue virus capsid protein: design and mechanism of action," The FEBS Journal, vol. 281, no. 1, pp. 191-215, 2014.

[20] K. Watanabe, M. Harada-Shiba, A. Suzuki et al., "In vivo siRNA delivery with dendritic poly(l-lysine) for the treatment of hypercholesterolemia," Molecular BioSystems, vol. 5, no. 11, pp. 1306-1310, 2009.

[21] N. W. S. Kam, Z. Liu, and H. Dai, "Functionalization of carbon nanotubes via cleavable disulfide bonds for efficient intracellular delivery of siRNA and potent gene silencing," Journal of the American Chemical Society, vol. 127, no. 36, pp. 12492-12493, 2005.

[22] A. Akinc, W. Querbes, S. De et al., "Targeted delivery of RNAi therapeutics with endogenous and exogenous ligandbased mechanisms," Molecular Therapy, vol. 18, no. 7, pp. 13571364, 2010.

[23] M. Saraswathy and S. Gong, "Recent developments in the codelivery of siRNA and small molecule anticancer drugs for cancer treatment," Materials Today, vol. 17, no. 6, pp. 298-306, 2014.

[24] E. R. Gillies and J. M. J. Fréchet, "Dendrimers and dendritic polymers in drug delivery," Drug Discovery Today, vol. 10, no. 1, pp. 35-43, 2005.

[25] A. D. Frankel and C. O. Pabo, "Cellular uptake of the tat protein from human immunodeficiency virus," Cell, vol. 55, no. 6, pp. 1189-1193, 1988.

[26] S. Reissmann, "Cell penetration: scope and limitations by the application of cell-penetrating peptides," Journal of Peptide Science, vol. 20, no. 10, pp. 760-784, 2014.

[27] Y. Xiong and M. Sundaralingam, "Protein-nucleic acid interaction: major groove recognition determinants," in Encyclopedia of Life Sciences, John Wiley \& Sons Ltd, Chichester, UK, 2001.

[28] R. Schleif, "DNA binding by proteins," Science, vol. 241, no. 4870, pp. 1182-1187, 1988.

[29] J. M. Ryter and S. C. Schultz, "Molecular basis of doublestranded RNA-protein interactions: structure of a dsRNAbinding domain complexed with dsRNA," The EMBO Journal, vol. 17, no. 24, pp. 7505-7513, 1998. 
[30] J.-M. Crowet, L. Lins, S. Deshayes et al., "Modeling of non-covalent complexes of the cell-penetrating peptide CADY and its siRNA cargo," Biochimica et Biophysica ActaBiomembranes, vol. 1828, no. 2, pp. 499-509, 2013.

[31] J. Fohrer, M. Hennig, and T. Carlomagno, "Influence of the 2 hydroxyl group conformation on the stability of A-form helices in RNA," Journal of Molecular Biology, vol. 356, no. 2, pp. 280287, 2006.

[32] S. El Andaloussi, T. Lehto, I. Mäger et al., "Design of a peptidebased vector, PepFect6, for efficient delivery of siRNA in cell culture and systemically in vivo," Nucleic Acids Research, vol. 39, no. 9, pp. 3972-3987, 2011.

[33] P. Lundberg, S. El-Andaloussi, T. Sütlü, H. Johansson, and Ü. Langel, "Delivery of short interfering RNA using endosomolytic cell-penetrating peptides," The FASEB Journal, vol. 21, no. 11, pp. 2664-2671, 2007.

[34] K. Padari, K. Koppel, A. Lorents et al., "S413-PV cell-penetrating peptide forms nanoparticle-like structures to gain entry into cells," Bioconjugate Chemistry, vol. 21, no. 4, pp. 774-783, 2010.

[35] J. Thomas and A. Macke David, "Molecular modeling of nucleic acids," in ACS Symposium Series, NB. Leontis and J. SantaLucia, Eds., vol. 682, American Chemical Society, Washington, DC, USA, 1997.

[36] Y. Shen, J. Maupetit, P. Derreumaux, and P. Tufféry, "Improved PEP-FOLD approach for peptide and miniprotein structure prediction," Journal of Chemical Theory and Computation, vol. 10, no. 10, pp. 4745-4758, 2014.

[37] J. Maupetit, P. Derreumaux, and P. Tuffery, "PEP-FOLD: an online resource for de novo peptide structure prediction," Nucleic Acids Research, vol. 37, no. 2, pp. W498-W503, 2009.

[38] J. Maupetit, P. Derreumaux, and P. Tufféry, "A fast method for large-scale de novo peptide and miniprotein structure prediction," Journal of Computational Chemistry, vol. 31, no. 4, pp. 726-738, 2010.

[39] J. C. Phillips, R. Braun, W. Wang et al., "Scalable molecular dynamics with NAMD," Journal of Computational Chemistry, vol. 26, no. 16, pp. 1781-1802, 2005.

[40] S. R. Comeau, D. W. Gatchell, S. Vajda, and C. J. Camacho, "ClusPro: a fully automated algorithm for protein-protein docking," Nucleic Acids Research, vol. 32, supplement 2, pp. W96-W99, 2004.

[41] S. R. Comeau, D. W. Gatchell, S. Vajda, and C. J. Camacho, "ClusPro: an automated docking and discrimination method for the prediction of protein complexes," Bioinformatics, vol. 20, no. 1, pp. 45-50, 2004.

[42] H. J. C. Berendsen, D. van der Spoel, and R. van Drunen, "GROMACS: a message-passing parallel molecular dynamics implementation," Computer Physics Communications, vol. 91, no. 1-3, pp. 43-56, 1995.

[43] K. Vanommeslaeghe, E. Hatcher, C. Acharya et al., "CHARMM general force field: A force field for drug-like molecules compatible with the CHARMM all-atom additive biological force fields," Journal of Computational Chemistry, vol. 31, no. 4, pp. 671-690, 2010.

[44] A. Joliot, C. Pernelle, H. Deagostini-Bazin, and A. Prochiantz, "Antennapedia homeobox peptide regulates neural morphogenesis," Proceedings of the National Academy of Sciences of the United States of America, vol. 88, no. 5, pp. 1864-1868, 1991.

[45] D. Derossi, A. H. Joliot, G. Chassaing, and A. Prochiantz, "The third helix of the Antennapedia homeodomain translocates through biological membranes," Journal of Biological Chemistry, vol. 269, no. 14, pp. 10444-10450, 1994.
[46] E. Vivès, P. Brodin, and B. Lebleu, "A truncated HIV-1 Tat protein basic domain rapidly translocates through the plasma membrane and accumulates in the cell nucleus," The Journal of Biological Chemistry, vol. 272, no. 25, pp. 16010-16017, 1997.

[47] I. A. Ignatovich, E. B. Dizhe, A. V. Pavlotskaya et al., "Complexes of plasmid DNA with basic domain 47-57 of the HIV-1 tat protein are transferred to mammalian cells by endocytosismediated pathways," Journal of Biological Chemistry, vol. 278, no. 43, pp. 42625-42636, 2003.

[48] S. Futaki, T. Suzuki, W. Ohashi et al., "Arginine-rich peptides: an abundant source of membrane-permeable peptides having potential as carriers for intracellular protein delivery," Journal of Biological Chemistry, vol. 276, no. 8, pp. 5836-5840, 2001.

[49] I. Nakase, T. Takeuchi, G. Tanaka, and S. Futaki, "Methodological and cellular aspects that govern the internalization mechanisms of arginine-rich cell-penetrating peptides," Advanced Drug Delivery Reviews, vol. 60, no. 4-5, pp. 598-607, 2008.

[50] R. Tan and A. D. Frankel, "Structural variety of arginine-rich RNA-binding peptides," Proceedings of the National Academy of Sciences of the United States of America, vol. 92, no. 12, pp. 52825286, 1995.

[51] S. Futaki, "Membrane-permeable arginine-rich peptides and the translocation mechanisms," Advanced Drug Delivery Reviews, vol. 57, no. 4, pp. 547-558, 2005.

[52] M. Pooga, M. Hällbrink, M. Zorko, and Ü. Langel, "Cell penetration by transportan," The FASEB Journal, vol. 12, no. 1, pp. 67-77, 1998.

[53] A. Elmquist, M. Lindgren, T. Bartfai, and Ü. Langel, "Vecadherin-derived cell-penetrating peptide, pVEC with carrier functions," Experimental Cell Research, vol. 269, no. 2, pp. 237244, 2001.

[54] A. Elmquist, M. Hansen, and Ü. Langel, "Structure-activity relationship study of the cell-penetrating peptide pVECde pVEC," Biochimica et Biophysica Acta-Biomembranes, vol. 1758, no. 6, pp. 721-729, 2006.

[55] I. O. Akdag and E. Ozkirimli, "The uptake mechanism of the cell-penetrating pVEC peptide," Journal of Chemistry, vol. 2013, Article ID 851915, 9 pages, 2013.

[56] A. Elmquist and Ü. Langel, "In vitro uptake and stability study of pVEC and its all-D analog," Biological Chemistry, vol. 384, no. 3, pp. 387-393, 2003.

[57] M. C. Morris, P. Vidal, L. Chaloin, F. Heitz, and G. Divita, "A new peptide vector for efficient delivery of oligonucleotides into mammalian cells," Nucleic Acids Research, vol. 25, no. 14, pp. 2730-2736, 1997.

[58] L. Crombez, M. C. Morris, S. Dufort et al., "Targeting cyclin B1 through peptide-based delivery of siRNA prevents tumour growth," Nucleic Acids Research, vol. 37, no. 14, pp. 4559-4569, 2009.

[59] C. Palm-Apergi, A. Lorents, K. Padari, M. Pooga, and M. Hällbrink, "The membrane repair response masks membrane disturbances caused by cell-penetrating peptide uptake," The FASEB Journal, vol. 23, no. 1, pp. 214-223, 2009.

[60] L. Crombez, G. Aldrian-Herrada, K. Konate et al., "A new potent secondary amphipathic cell-penetrating peptide for siRNA delivery into mammalian cells," Molecular Therapy, vol. 17, no. 1, pp. 95-103, 2009.

[61] J. Hoyer, U. Schatzschneider, M. Schulz-Siegmund, and I. Neundorf, "Dimerization of a cell-penetrating peptide leads to enhanced cellular uptake and drug delivery," Beilstein Journal of Organic Chemistry, vol. 8, pp. 1788-1797, 2012. 
[62] M. Jafari, D. N. Karunaratne, C. M. Sweeting, and P. Chen, "Modification of a designed amphipathic cell-penetrating peptide and its effect on solubility, secondary structure, and uptake efficiency," Biochemistry, vol. 52, no. 20, pp. 3428-3435, 2013.

[63] C. J. Wrighton, "Inhibition of endothelial cell activation by adenovirus-mediated expression of I kappa B alpha, an inhibitor of the transcription factor NF-kappa B," Journal of Experimental Medicine, vol. 183, no. 3, pp. 1013-1022, 1996.

[64] X.-Y. Liu, S. Timmons, Y.-Z. Lin, and J. Hawiger, "Identification of a functionally important sequence in the cytoplasmic tail of integrin beta 3 by using cell-permeable peptide analogs," Proceedings of the National Academy of Sciences of the United States of America, vol. 93, no. 21, pp. 11819-11824, 1996.

[65] L. Zhang, T. R. Torgerson, X.-Y. Liu et al., "Preparation of functionally active cell-permeable peptides by single-step ligation of two peptide modules," Proceedings of the National Academy of Sciences of the United States of America, vol. 95, no. 16, pp. 91849189, 1998.

[66] E. Bleifuss, T. Kammertoens, A. Hutloff et al., "The translocation motif of hepatitis B virus improves protein vaccination," Cellular and Molecular Life Sciences, vol. 63, no. 5, pp. 627-635, 2006.

[67] M. Rojas, J. P. Donahue, Z. Tan, and Y.-Z. Lin, "Genetic engineering of proteins with cell membrane permeability," Nature Biotechnology, vol. 16, no. 4, pp. 370-375, 1998.

[68] M. C. Morris, L. Chaloin, J. Méry, F. Heitz, and G. Divita, “A novel potent strategy for gene delivery using a single peptide vector as a carrier," Nucleic Acids Research, vol. 27, no. 17, pp. 3510-3517, 1999.

[69] M. Rhee and P. Davis, "Mechanism of uptake of C105Y, a novel cell-penetrating peptide," Journal of Biological Chemistry, vol. 281, no. 2, pp. 1233-1240, 2006.

[70] D. Kozakov, R. Brenke, S. R. Comeau, and S. Vajda, "PIPER: an FFT-based protein docking program with pairwise potentials," Proteins: Structure, Function, and Bioinformatics, vol. 65, no. 2, pp. 392-406, 2006.

[71] L. Pauling, R. B. Corey, and H. R. Branson, "The structure of proteins; two hydrogen-bonded helical configurations of the polypeptide chain," Proceedings of the National Academy of Sciences of the United States of America, vol. 37, no. 4, pp. 205211, 1951.

[72] E. Eiríksdóttir, K. Konate, Ü. Langel, G. Divita, and S. Deshayes, "Secondary structure of cell-penetrating peptides controls membrane interaction and insertion," Biochimica et Biophysica Acta - Biomembranes, vol. 1798, no. 6, pp. 1119-1128, 2010.

[73] F. Madani, S. Lindberg, Ü. Langel, A. Gräslund, and S. Futaki, "Mechanisms of cellular uptake of cell-penetrating peptides," Journal of Biophysics, vol. 2011, Article ID 414729, 10 pages, 2011. 

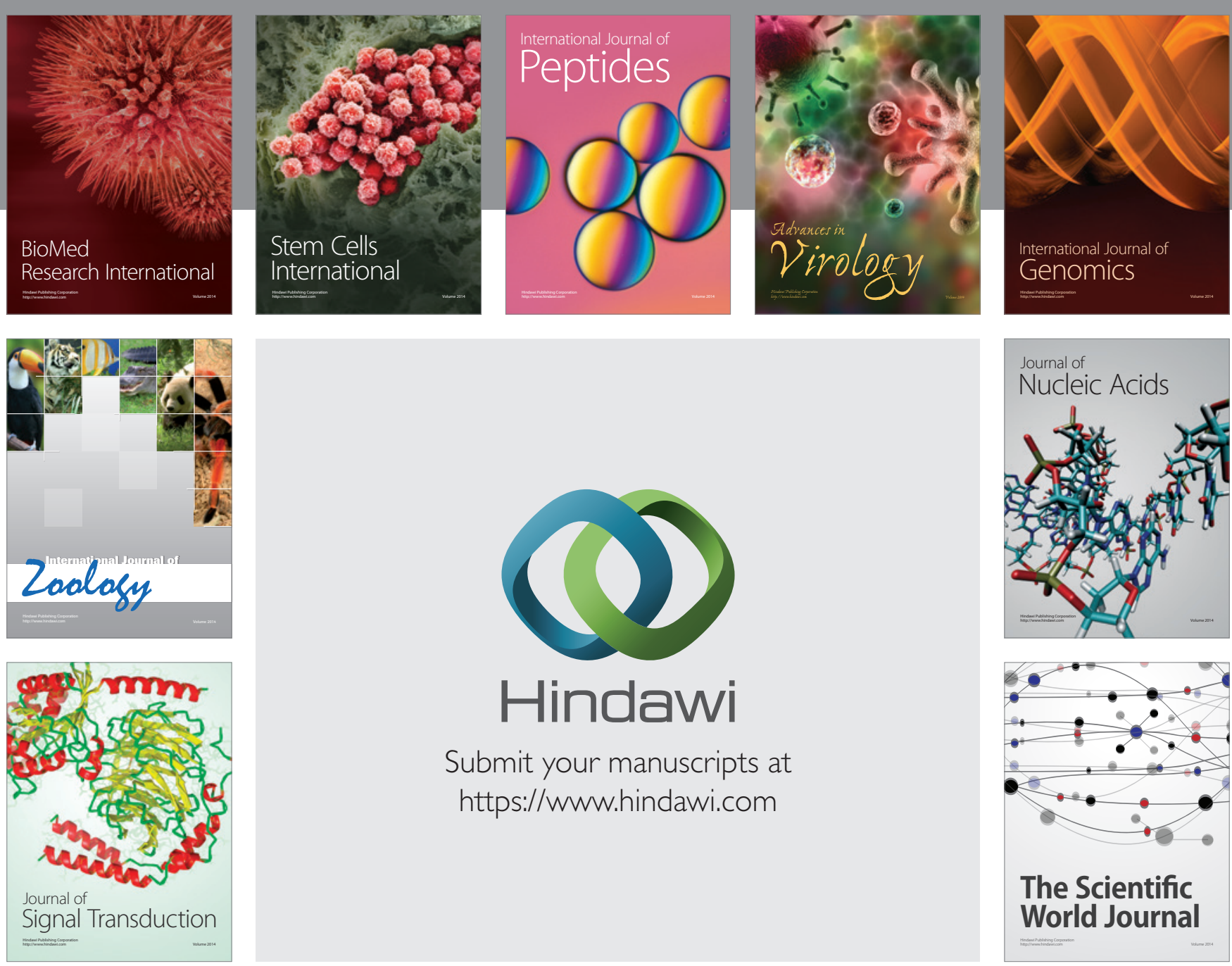

Submit your manuscripts at

https://www.hindawi.com
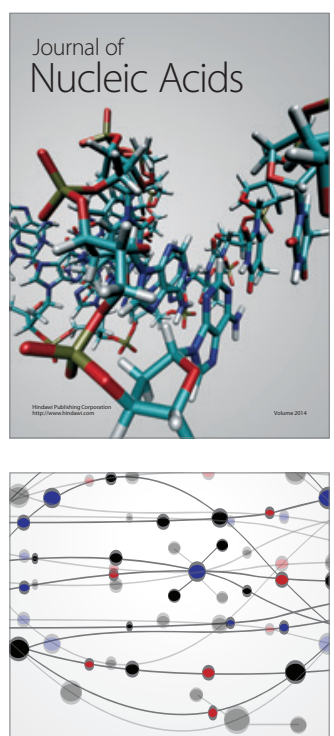

The Scientific World Journal
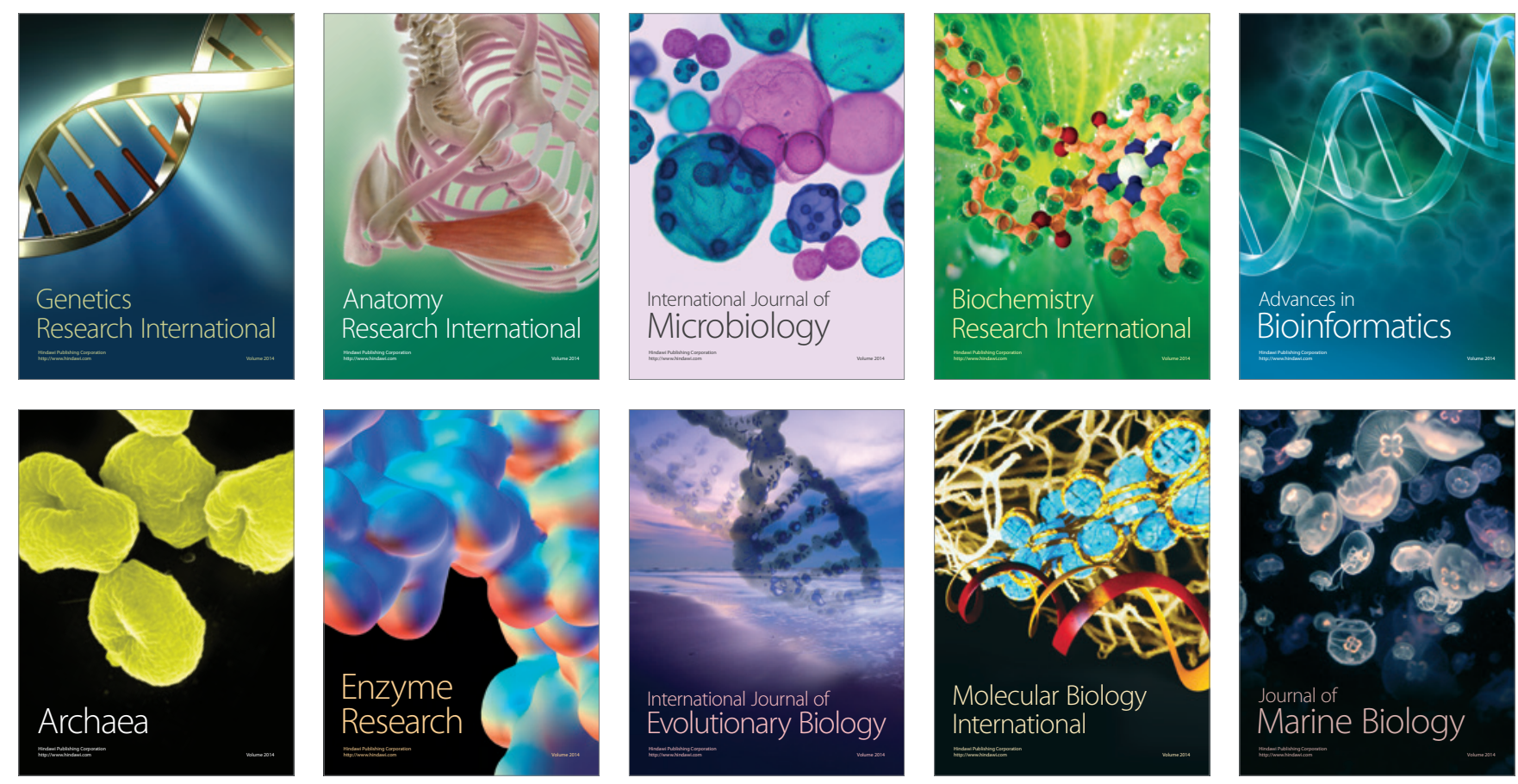